\title{
Unusual animal behaviour before earthquakes and multiple parameter monitoring in Western Piedmont
}

\author{
Giovanna de Liso ${ }^{1,2,3, *}$, Cristiano Fidani ${ }^{1,4}$, Andrea Viotto ${ }^{1}$ \\ ${ }^{1}$ Seismic Precursors Study Center, Associazione Culturale "Le Nuove Muse”, Via Servera, 16, 10066, Torre Pellice, Italy \\ ${ }^{2}$ Istituto di Alta formazione artistica e musicale "G. F. Ghedini”, Cuneo, Italy \\ ${ }^{3}$ Voce Pinerolese, P. S. Donato 30, 10064, Pinerolo, Italy \\ ${ }^{4}$ Central Italy Electromagnetic Network, 63847 San Procolo, Fermo, Italy
}

\section{Email address:}

giovannadelisomr53@yahoo.it (G. de Liso), direttore@vocepinerolese.it (G. de Liso), c.fidani@virgilio.it (C. Fidani)

\section{To cite this article:}

Giovanna de Liso, Cristiano Fidani, Andrea Viotto. Unusual Animal Behaviour before Earthquakes and Multiple Parameter Monitoring in Western Piedmont. Earth Science. Vol. 3, No. 1, 2014, pp. 14-25. doi: 10.11648/j.earth.20140301.13

\begin{abstract}
The complex synergy of various non-seismic precursor phenomena renders difficult to specify what are the chemical and physical parameters, whose variations give more problems to the animal and plant kingdoms. Local seismic events are generally seldom announced by anomalous animal behaviours. Unfortunately we do not understand animal languages or their meaningful vocal modulations. Moreover, many animal alarms are not acknowledged. A number of animal and human observations in Northern Italy are reported, which can suggests physical observations potentially connected with seismic events. The study of seismic precursors is still in its infancy, the error margin on temporal and spatial forecast is still large and must be evaluated. Being so, a multiple parameter physical monitoring started recently in Western Piedmont, which is useful to propose the study of seismic precursors possibly linked to animal behaviour. Electric and magnetic detectors were operating together with alpha particle and acoustic detectors, while a collection of anomalous biological and meteorological observations were taken. Variations in the recent years of the magnetic declination revealed to be a good candidate to precursor, related to the direction of compression, traction and stretching on rocks, even if the geographic localization of future earthquakes is still impossible. In case of some local unusual animal behaviours it can suggest the occurrence of a local seismic event with epicentre distance $\leq 100 \mathrm{~km}$. Statistical information on warnings from local dogs and cats are given.
\end{abstract}

Keywords: Unusual Animal Behavior, Earthquake, Electric Monitoring, Magnetic Monitoring, Radon Monitoring, Sound Monitoring

\section{Introduction}

An experimental study centre about an eventual correlation between chemical and physical seismic precursors and unusual animal behaviour needs a sparsely populated location, where it is possible to observe domestic and wild animals. With a multiple parameter monitoring and statistic considerations "a posteriori" taking place, it is very important to study the local geophysical answer to earthquakes. This answer is the total variation of physical parameters such as atmosphere and ground temperatures, humidity, pressure, wind, rain, atmospheric and ground electric fields, magnetic declination, neutron flux, radon emission and acoustic vibration.

In order to collect the major number of observations on human, animal and plant health it is also necessary to have a good dialogue with local people. The journal "Voce
Pinerolese" and the cultural association "Le Nuove Muse" give to the "Seismic Precursors Study Centre" (SPSC) the possibility to receive, almost in real time, observations on unusual animal behaviour. Furthermore, other unusual phenomena, like Earthquake Lights (EQL), were collected from people in the area of Pinerolo. SPSC, see Fig 1a, is located in Torre Pellice $\left(44^{\circ} 49^{\prime} 235^{\prime \prime} \mathrm{N}, 7^{\circ} 123^{\prime} 04^{\prime \prime} \mathrm{E}\right.$, Western Piedmont, NW Italy) at $699 \mathrm{~m}$ above sea level on Vandalino Mountain, not too far from an abandoned iron mine, near a particular "geological sanctuary" on "Castelluzzo" peak [1]. This place is ideal for this study, since the area has a moderate seismic activity. The recent classification of the seismic risk in this area is $3 \mathrm{~S}$. In January 2012, a new Italian legislative measure classified Italian Municipalities in four main categories on the basis of their seismic risk. The seismic risk is a number calculated on the basis of Peak Ground Acceleration (PGA) 
and on the frequency and intensity of seismic events [2]. Zone 1 has a high seismic activity, with PGA over $0.25 \mathrm{~g}$, zone 2 has a moderate seismic activity, with PGA between 0.15 and $0.25 \mathrm{~g}$. Zone 3 has a low seismic activity $(0.3$ earthquakes/year with $M \geq 4$ and $M<6$ in the records), with PGA between 0.05 and $0.15 \mathrm{~g}$. Zone 4 has a very low seismic activity, with PGA $<0.05$ g. Between the zones 2 and 3 there is the zone $3 \mathrm{~S}$, which has a moderate seismic activity, but the geologic conformation can create heavy damages. Anti-seismic building regulations in force in zone 2 must also be observed in zone 3S. The recent classification divides Italy in micro-zones, with a step of 10 $\mathrm{km}$.
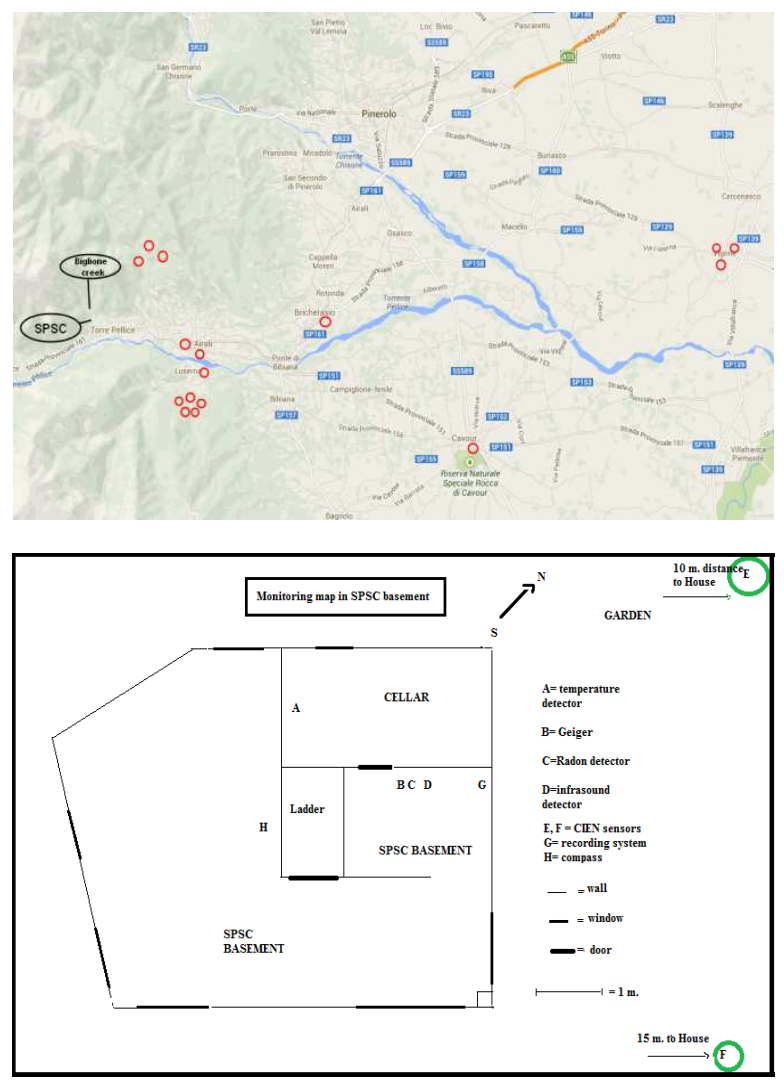

Figure 1. (a) radon Monitoring map; radon-meters in SPSC and in the locations inside the red circles; the map was retrieved from Google Maps website http://maps.google.it/. (b) disposition of the monitoring devices in SPSC.

In spite of today's moderate seismic activity, in the past times Pinerolo, Val Chisone, Val Pellice and Val Germanasca were nevertheless a theatre of earthquakes with high magnitude, as it can be seen in the local historical chronicles: on April $2^{\text {nd }}, 1808$, at 17:43 LT, an earthquake of magnitude $M=5.7$ and intensity of 8 in the Mercalli Cancani Sieberg scale, with epicentre in Luserna San Giovanni [3]. Despite the earthquake destroyed almost all the houses, only four were the victims. At the moment of the earthquake most farmers were outside, working in the fields. Some people inside houses saved themselves, due to the agitation of their cows a few seconds before the seismic shock. This information appear both from oral tradition and from a few letters [4]. Then, on April 16th, 1808, another earthquake occurred with the same magnitude. The day before, people saw a few balls of light on Vandalino and near Pellice river. It was notable that two hundred centuries later, as reported in the observational section of this work, observations regarding similar phenomena were made before earthquakes in the same region.

The next section is dedicated to the biological collection data and instrumental methods. The third section summarise the anomalous animal behaviours. A statistical analysis of dog and cat unusual behaviours is presented in section four. Section five outlines the conclusions in connection with the Vandalino Mountain, especially the area of Castelluzzo and Bonnet, which is rich in augen-gneiss, of eruptive origin, biotite, ophiolite, zeolite, pechblenda and "Luserna Stone" (gneiss) [1].

\section{Experimental Section}

\subsection{Monitoring and Observation Frequency}

The study of animal behaviour is conducted by the first Author with the following modalities:

- continuous observation of the behaviour of cats and dogs living in SPSC (in de Liso's house);

- continuous behaviour observation of insects and arachnids inside and outside de Liso's house;

- very frequent observation of the behaviour of wild animals, like birds, reptiles (water snakes), amphibious (two salamanders), mammals (two hedgehogs, a fox with sometimes its cubs), two squirrels, that habitually come out of the woods into a garden near SPSC to eat (this observation is season dependent);

- continuous hearing of languages of domestic and wild animals, on Mountain Vandalino, near and far from SPSC;

- a collection of sporadic observations by people, that collaborates with SPSC, in Val Pellice, Cavour and Rocca di Cavour, in the areas of Pinerolo and Cuneo, Italy; Rocca di Cavour is a little mountain, with a hole at the top: from this hole, sulphurous gas and radon sometimes come out;

- a comparison with other studies from different regions.

The observation of animal behaviours began in 1991 when it was noted that some unusual recurrences in animal behaviour occur before earthquakes. These observations were supported by a multi-parameter monitoring since 1998. During the period 2000-2005 Prof. Paola Michelin Lausarot from the Chemistry Department of Turin, collaborated with a radioactive monitoring one day a week, with a "Flux-gate Monitor" ( $\beta$ and $\gamma$ particles) and with a magnetic monitoring, using a Flux-master Monitor, a highly sensitive hand-held flux-gate magnetometer, made for the precise measurement of weak magnetic fields from $1 \mathrm{nT}$ to $200 \mu \mathrm{T}$ (DC to $1 \mathrm{kHz}$ ). Prof. Michelin also gave to 
the Chemistry Department water samples for radon measurements, taken in Valle Pellice. Since 2010, a station for ground electrical currents [5] was operative in Luserna San Giovanni $\left(44^{\circ} 48^{\prime} 59^{\prime \prime} \mathrm{N}, 7^{\circ} 14^{\prime} 18.77^{\prime \prime} \mathrm{E}^{\circ}\right.$, Western Piedmont, NW Italy) and, after 2012, a station of the Central Italy Electromagnetic Network (CIEN) was installed in Torre Pellice for Electromagnetic (EM) monitoring, together with a meteorological station [6], checking eventual analogies with different observations in Piedmont or other regions.

It is very important to know what are the physical and chemical parameters that before, during and after earthquakes can cause unusual animal behaviours, but they operate with a very complex synergism. This synergism was observed in Torre Pellice, with a monitoring of many physical parameters at the same time [7]. Many of our observations, of variations of physical and some chemical parameters and anomalous animal behaviour before earthquakes, are similar to those observed by Tsuneji Rikitake [8,9]. This likeness concerns changing of physical parameters, the drastic reduction of their variations a few hours before the first seismic shock, the prediction of future earthquakes by anomalous animal behaviours.

It is also important to distinguish winter or cold seasons from summer or warm seasons, since animals react to seismic phenomena not always all at the same manner, this being dependent on seasonal behavior. For example, the animals that go in hibernation can better show with their early awakening the unusual behaviour, that otherwise could not be noted.

\subsection{Instrumentation}

The monitoring in Torre Pellice has followed specific procedures. Starting in 1999, a once a week monitoring, in the zone of Castelluzzo, for radioactive and air temperature measures. The air temperature values were recorded from a big rock crack. A further monitoring started twice a day, in the basement of SPSC, see Figure 1b, for radioactivity, magnetic declination, magnetic induction variation, underground and subsoil temperature measures. Starting in 2000, a daily monitoring for radioactivity and air temperature measurements was undertaken during the night in the forest near SPSC. The air temperature values were recorded from a little rock crack and water temperature measurements were intermittently recorded in Biglione creek, see Fig 1a. Since 2011, a continuous radon monitoring started in the basement of SPSC. Since 2012, irregular radon monitoring started by dosimeters, placed in some places inside and outside (garden) SPSC. Since July 2012, weekly measurements of water $\mathrm{pH}$ were started in the garden near SPSC and in the Biglione creek. The instruments in SPSC basement are:

- 1 Geiger counter for $\beta$ and $\gamma$ particles "Ю нчмер SKM 05" (Figure 1a and b), placed on a layer of gneiss;

- 1 multi-parameter detector TreField EM Meter" (Figure 1b), it was used only the magnetic monitoring of this, with a magnetic induction, $0-100 \mu \mathrm{T}$, the instrument is positioned on a gneiss surface parallel to the floor;

- $\quad 1$ thermometer (sensitivity of $\pm 0.1^{\circ} \mathrm{C}$ );

- 1 thermometer TM-917 DICOM (from $-100{ }^{\circ} \mathrm{C}$ to $+132{ }^{\circ} \mathrm{C}, \pm 0.1^{\circ} \mathrm{C}$ ), monitoring every $0.4 \mathrm{sec}$, , with PC connection, placed in a cellar, at a depth of 2 meters in the soil;

- 4 compasses "Virginia" 6036VA, liquid filled lensatic compass, two on wood surfaces and two on big iron surfaces, exalting the variations of the magnetic orientation; these compasses are at the centre of iron surfaces, for a better homogeneity of directions of vectors of the magnetic field;

- many radon dosimeters (Geoex);

- 1 Radon-meter detector (Geoex, model 1027), placed on a table, at a height of $1.20 \mathrm{~m}$ from the floor, in the basement;

- CIEN electrodes;

- 1 Meteorological Station, type PCE-FWS 20, on the roof of the house;

- 1 Infra-sound detector (model "Infrasonic 200", Aetech, with a continuous monitoring - 5 samples/second): it is placed on a table, in SPSC basement, at $1.20 \mathrm{~m}$ from the floor and $5 \mathrm{~cm}$ distance to a wall of the basement.

Starting in May 2012, a continuous monitoring of horizontal components of the electric field by CIEN together with temperature, humidity, pressure, rain and wind was measured by a Meteorological Station. The actual CIEN update is shown in Figure 2, for a total of 12 stations, where the Avigliano Umbro, Città di Castello and Gubbio stations were recently added respectively in Terni and Perugia Provinces, Central Italy. CIEN instruments are made up of two principal parts [10-13]: the outdoor sensor and the indoor recording system. The sensor is composed of electrode wires with electronics that prepare the signals. Electrode wires must be positioned outside since they are responsible for picking up EM signals in the atmosphere. The recording system is realized by a standard PC audio card with the necessary software to carry out a real time analysis and store data. Spectrum Laboratory free software (at http://www.qsl.net/dl4yhf/spectra1.html) is used to fix the recording parameters and to analyse the signals using Fast Fourier Transform. A couple of wide band amplifiers were operative in ELF, in the range from 4 to $1000 \mathrm{~Hz}$, VLF and LF, in the range from 1 to $25 \mathrm{kHz}$ and some station from 1 to $50-100 \mathrm{kHz}$, see Figure 3. Characteristic ELF signals are monitored in relation to seismic activity [14]. VLF and LF range allows to monitor several sub-ionospheric signals from different VLF and LF transmitters overlapping in the same channels, which is a necessary feature of a reliable system that is able to verify a single channel perturbation from at least two signals. Additionally, differently located sub-ionospheric channel monitoring stations of CIEN are able to realise overlapping (see Figure 1 of [6]). 


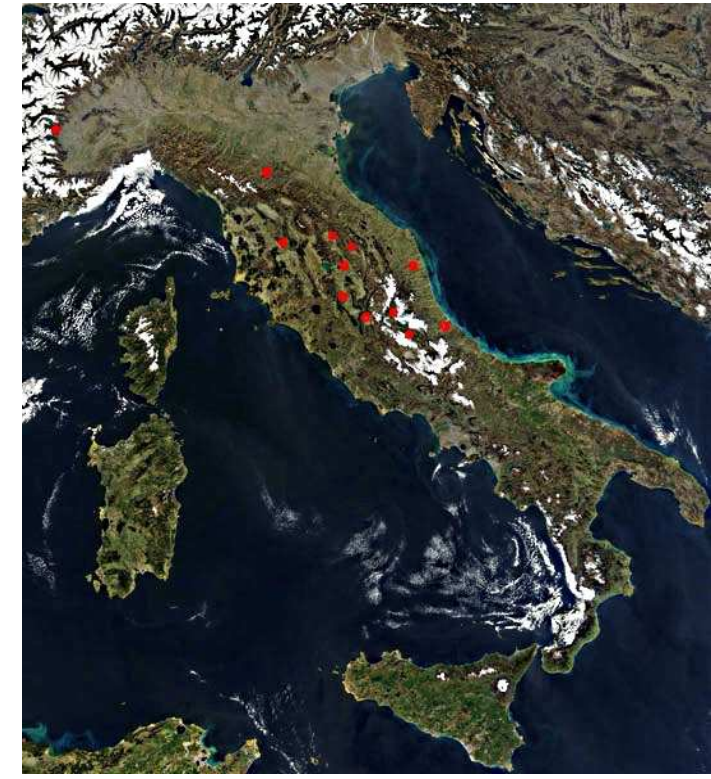

Figure 2. The positions of the CIEN Stations.

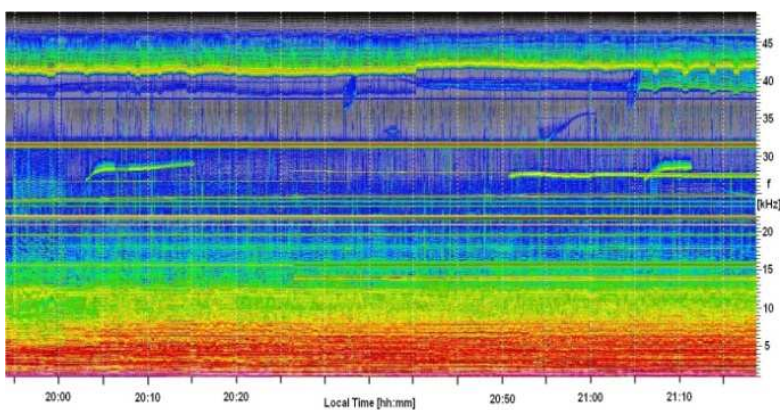

Figure 3. The dynamical spectra between 1 and $50 \mathrm{kHz}$, recorded at SPCS by CIEN antenna; colors describes the electric field intensity and horizontal lines represents radio transmitters: $400 \mathrm{~kW}$ in Anthorn/Skelton, England at $19.6 \mathrm{kHz}$ and $22.1 \mathrm{kHz} ; 400 \mathrm{~kW}$ in Saint-Assise, France at 20.9 $\mathrm{kHz} ; 800 \mathrm{~kW}$ in Rhauderfehn, Germany at $23.4 \mathrm{kHz} ; 1,000 \mathrm{~kW}$ in Culter, Maine at $24.0 \mathrm{kHz} ; 192 \mathrm{~kW}$ in Seattle, Washington at $24.6 \mathrm{kHz} ; 100 \mathrm{~kW}$ in Keflavik, Iceland at $37.5 \mathrm{kHz}$; Niscemi, Sicily, Italy at $45.9 \mathrm{kHz}$.

The monitoring in Luserna San Giovanni since 2011 is also characterised by a continuous measurement of ground electrical currents and recording of mechanic seismic shocks. The instruments in Luserna San Giovanni Station are at about $4 \mathrm{~km}$ East of SPSC (see the two coordinates mentioned before). They are:

- 1 Geiger counter for $\beta$ and $\gamma$ particles, Inspector Alert, International MEDCON Inc.;

- 1 Trifield magnetic detector;

- 1 compass, "Virginia" 6036VA, liquid filled lensatic compass;

- 1 electric field detector, monitoring every 2 seconds, from $\mathrm{DC}$ to $50 \mathrm{~Hz}$, measured in $\mathrm{pV}$, magnified 250,000 time [5]. The two copper drills are $50 \mathrm{~cm}$ long and placed at a depth of $20 \mathrm{~cm}$ in the cellar subsoil.

- 1 gravity-meter with an hanging pendulum [15]; an example of graphic of gravity-meter monitoring was reported in Figure 4.

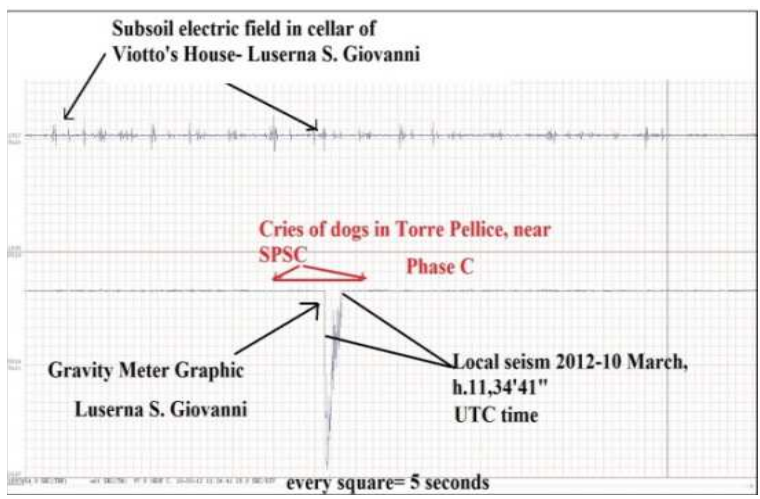

Figure 4. Electric field graphic and contemporaneous gravity-meter graphic, recorded in Luserna San Giovanni, phase C observed near SPSC, in Torre Pellice; the mechanical variations on $Z$ axis are recorded in $\mu V$ by an iron-core inductor.

\section{Unusual Animal Behaviour before Earthquakes}

The SPSC is placed located in de Liso's house, near a forest, at a distance of $70 \mathrm{~m}$ from the Biglione creek, see Figure 1a. There are several farms nearby, so it is possible to observe everyday farm and wild animals. Considering the behaviour, the animal language can be better understood if the farm and wild animals are observed in their habitual environment. Even in case of a moderate local seismic activity, the various precursors and animal reactions appear to be connected with geologic structures. When the epicentre distance to SPSC is inferior to 20-25 $\mathrm{km}$, with a low magnitude $(\mathrm{M} \leq 1)$, some unusual animal behaviours was always noted, a few days, a few hours and a few seconds before the seismic event, with different modalities for the three cases described in what follows. But the same unusual animal behaviours before earthquakes with epicentre distances to SPSC progressively increasing was observed, if there was also a progressive increase in the magnitude.

The anomalous animal behaviours were observed with the following types:

(1) particular vocal language (in 3.1, 3.2);

(2) non-vocal anomalous behaviour different from the usual pattern (in 3.3, 3.4, 3.6, 3.7, 3.8, 3.9);

(3) problems to health and safety (in $3.5,3.10$ ).

In (1) the acoustic perception of vocal alarms is more concise, it regards a large area and it is easier to note. It was observed that the animal vocal alarm was a particular vocal language, which seems directed to their species. It is an individual answer to the danger or a co-ordinate answer of the leading animal to the same danger. It can be supposed that the vocal animal alarm is a "thought answer", which expresses oneself as a dialogue with other animals or with humans. It must be not confused with other unusual animal behaviours that can be observed 15-20 hours, and sometimes a few days, before a seismic event. It occurred contemporaneously with the magnetic sudden 
commencement [16], which is the sudden beginning of a magnetic storm in declination and intensity. During this first moment it was noted unusual flight behaviours, domestic animals were nervous and insects and arachnids were more aggressive, until magnetic variations were great. These behaviours were not coordinated with the group.

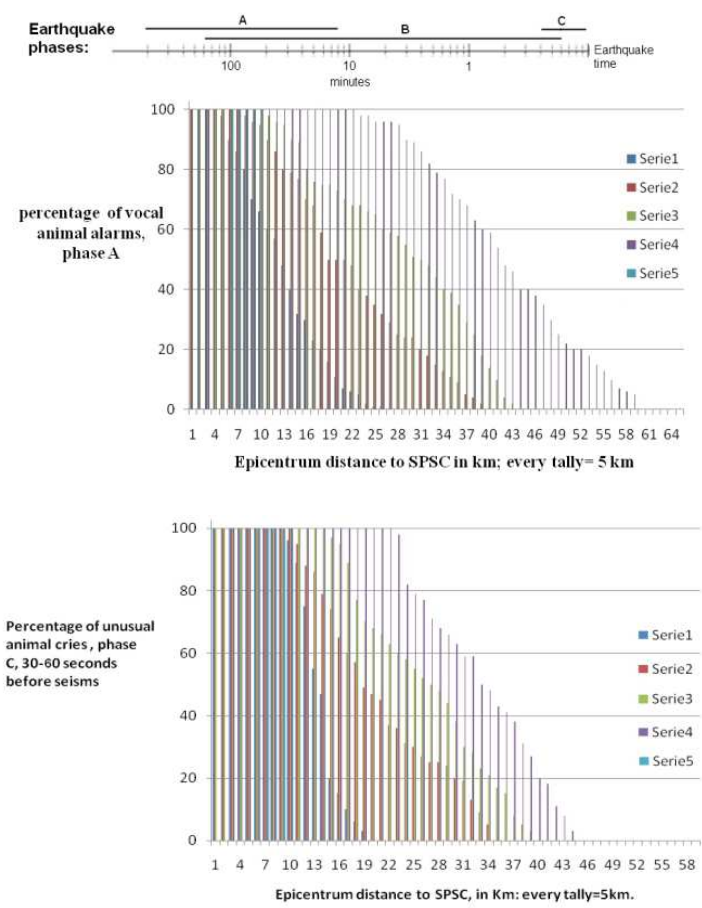

Figure 5. (a) percentage of unusual animal cries, phase A (3-5 hours before earthquakes), in relation to epicentre distance to SPSC and to magnitude; (b) percentage of unusual animal cries, phase C (30-60 seconds before earthquakes), in relation to epicentre distance to SPSC and in relation to magnitude; series 1: $0<M \leq 1$; series 2 : $1<M \leq 2$; series 3 . $2<M \leq 3$; series 4: $3<M \leq 4$; series 5: $4<M \leq 5$; phases $A, B$ and $C$ indicated on top.

A particular tripartite sequence in the vocal alarms of domestic animals and birds was noted: phase A, lasting up to 2 hours, with shrills and high sounds, from 30 minutes until 10 hours before the earthquake, then, when cries stop simultaneously, phase B follows, with a strange and worry silence; finally phase $C$, with animal cries normally 20-40 seconds before the earthquakes, stopping few seconds before the shock. The phase $\mathrm{C}$ is corroborated by the observations of other researchers in case of other earthquakes [8,17-21]. The vocal animal alarms beginning up to 10 hours before local earthquakes, sometimes before distant earthquakes if the future magnitude is great, were contemporaneous to drastic reduction of variations in intensity and declination of the magnetic field and of radioactivity values. So, Figure $5 \mathrm{a}$ and $\mathrm{b}$ resume an interesting relation between seismic epicentre distances to SPSC, magnitude and percentage of unusual animal behaviours, in relation to domestic animal cries and to bird songs, noted before the same seismic event. Obviously, unusual animal behaviours can be only taken in account for those species which normal behaviour was known.

\subsection{Animal Alarms with Shrill and High Sounds, 3-5 Hours before the Earthquake: Phase $A$ and $B$}

A few hours and sometimes days before seismic events, animal agitation is now well known in scientific literature. It was supposed that this behaviour is possibly due to ultra-sounds emitted by rocks, or to magnetic variation, or due to the presence of dangerous gases [22]. The emission of ultra-sounds before rock fractures, was demonstrated with the experimental work on "Luserna stone" of Prof. Carpinteri or Turin Politecnico [23]. But now we do not know the times of ultrasound emission before rock fractures during local earthquakes.

During phase A, dogs, cats, cattle, sheep, equines, bats, birds cry all together simultaneously, for a long time and sometime up to half an hour, with agitation, emitting shrills, howls or high sounds. Then, they stop their laments all together, with a stupefying synchrony [24]. This silence may last 3-5 hours before the local first seismic shock and it is strange and worry, like the quiet that precedes the storm. It is interesting to observe that dogs living in farms, as opposed to dogs that live in city apartments, at first ululate. These howls are similar to those they emit when they hear ambulances or church bells. Then, dog howls modulate in barking, at the same time, with short and repeated sounds. This barking is composed by two articulations with an ascendant order of frequencies for all dogs, but small sized dogs repeat the same vocalization more frequently in a minute. The two articulations form a dissonant interval. In case of ambulances or church bells only dogs cry, not other animals, and they stop their cries when ambulances or bells stop their sound: so dogs do not bark after (it is possible to know the journey of the ambulance by the howls of different dogs along the way). In case of seismic precursors, the barks after the howls are very prolonged and contemporaneous.
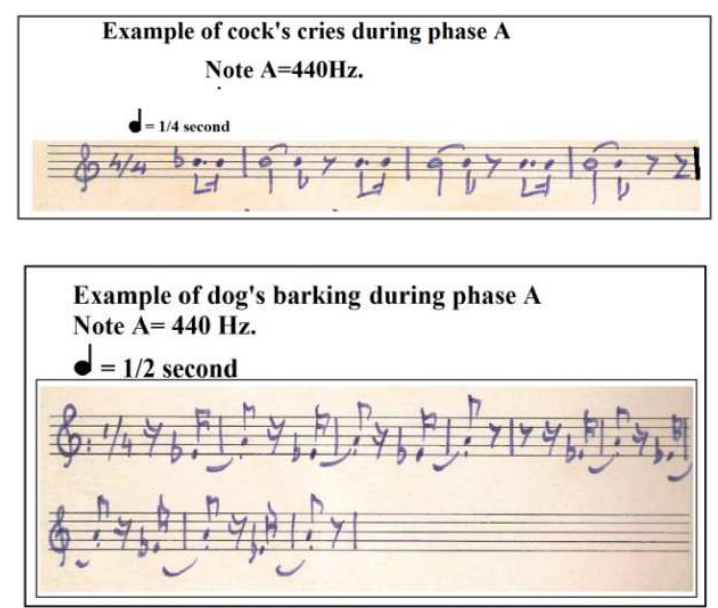

Figure 6. (a) Example of cock's cries during phase A; (b) Example of a dog's barking during phase $A$.

Cocks also shrill, but with a vocalization composed by three sounds, on the same intonation, the last of them prolonged. This short scheme of three sound is also 
repeated three times in sequences separated by short pauses, repeated many times with agitation. This agitation is similar to the same shown when there is a fox, a stone-marten or a hawk. But in this case the tripartite phrase is interrupted by other phrases modulated differently with melodic variations on the last sound: in this second case, cocks shrill in different moments according to their proximity to the "danger" and not all together and at the same time, as in seismic precursors. Also magpies and crows chatter with agitation, but with cries similar to the bipartite sounds of dogs (Figure 6a,b). This behaviour shows a tonal language for all these animals, it is important for us to distinguish the musical sequence. Figure 5a shows the percentage of animal cries before seismic events on the $y$ axis. The distance of hypocentre from SPSC is shown on the $\mathrm{x}$ axis. The colours are related to the magnitude of the earthquake. Animal vocal alarms lasted from half an hour to one hour and half, if the magnitude of following seismic events was more than 4. During phase A, a little magnetic intensity variations and drastic reductions in variations of the magnetic angle declination was recorded. Magnetic variations started with great variations, a few days or some weeks before earthquakes, the sudden commencement did not coincide with the beginning of phase A.

After the simultaneous vocal stop follows the worry silence, the phase B. During the phase B, a stop of magnetic and electric variations and the stop of radon emission were always noted.

\subsection{Animal Alarms a Few Seconds before Seismic Shocks and During the Seismic Rumbles: Phase C}

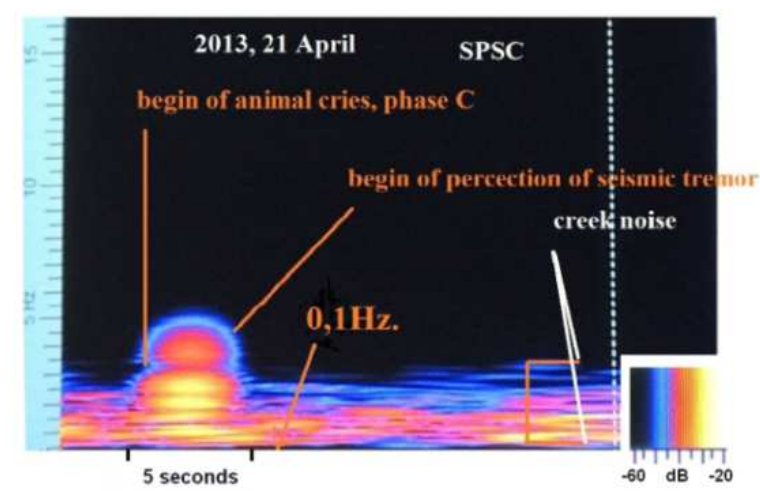

Figure 7. Data-logger elaboration of Infrasonic 200, local earthquakes of 2013, April 21 ${ }^{\text {st }}$, 11:53 UTC.

A continuous monitoring of infra-sounds was operating in SPSC: the background noise is comprised in the values 0.1-3 Hz, with several factor having an influence on it, like the Biglione creek nearby, whose flow variations can increase it up to $7 \mathrm{~Hz}$. During phase A, we were not able to record in SPSC any difference in the background noise that can be related to a seismic event. Then, 30-40 seconds before the seismic shock (phase C) infra-sound of 3.5-5 Hz were recorded, lasting a few seconds, with a particular progressive "crescendo" and then a progressive "decrescendo" of intensity. In the graphic representation on our recording device this sound pattern has a "Moorish arch" shape for the representation of frequencies $(\mathrm{Hz})$ while the colouring representing the intensity $(\mathrm{dB})$ shows a progressive increase in the values towards the centre of the arch (Figures 7 and 4).

In case of a seismic event, dogs, cats, cattle, sheep, equines, bats, birds cry all together when infra-sounds reach $3.5-5 \mathrm{~Hz}$ with the modalities described above, with low frequencies and with less synchrony in their calls. Normally, territorial competitions, sexual calls, dangers by intruders are expressed by domestic animals and birds with vocalizations not at the same time; these shrills are more various as succession of frequencies, with phrases more long between two pauses. Ache and loneliness (for dogs, cats cattle, equines) give long vocalizations on two or three descendent frequencies, repeated more and more with reducing intensity. These are the differences between anomalous animal sounds during pre-seismic phases and normal animal sounds.

The first Author Giovanna de Liso was saved by her dog, in a phase $C$, before a seismic event in Turin. When she was twelve, one minute before the seismic shock, that caused the ceiling of her room to fall down, her dog Lys, showing cries and agitation, held her with its paws under the architrave of a window, until the earthquake came. So, she stayed under the architrave and saved herself, because the architrave did not fall down. It would be interesting to know why the dog individuated the safest place under the architrave.

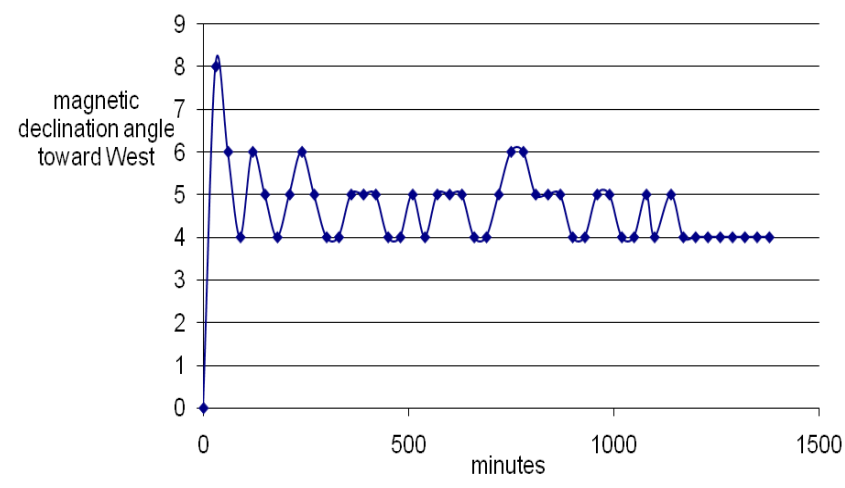

Figure 8. Variation of magnetic declination toward West, since sudden commencement, contemporaneous with the unusual flight pattern of a female blackbird, which banged against a barrier. June $5^{\text {th }}, 2009,10: 00$ LT.

\subsection{Unusual Flight Behaviour with Magnetic Sudden Variations}

A few days before Ferrara's area earthquake on May $20^{\text {th }}$ and $29^{\text {th }}, 2012, \mathrm{M}=6.0$ and 5.8 [25], and the L'Aquila earthquake on April 6, 2009, M=6.3 [26], it was observed, in some areas of Piedmont, unusual flight behaviours in female blackbirds, male tits and bats. In the morning of May $18^{\text {th }}$, 2012, 8:30 LT, instruments recorded in SPSC a declination variation $\delta$ of $7^{\circ}$ towards East. In the following moments a female blackbirds listed and banged against a 
wall of SPSC. A high magnetic declination variation of $15^{\circ}$ East two days before the L'Aquila earthquake was also observed. The geomagnetic situation the week before these earthquakes was quiet.

It is very important to individuate the right moment of the sudden magnetic commencement because it was the moment unusual flight behaviour observations. SPSC observations confirms that when geomagnetic perturbation is followed by a "small-storm" for a period of two-three hours, the magnetic storm showing worldwide with phenomena affecting the magnetosphere, it is always due to sun activity [27]. On other occasions, the sudden beginning can be followed for up to a few days by a variation of the absolute value of $\delta$ and by a variation of the intensity of the geomagnetic field. In these occasions, the needles of the SPSC compasses have a dampened oscillating motion around a new local North-South axes (Figure 8). At the beginning of $\delta$ oscillation, due to solar flares or to seismic activity unusual flight behaviour was often noted.

\subsection{Advanced Awakening from Hibernation}

Winter seismic activity is a better forewarning of the first shock because the precursor increase in soil and water temperature is well remarked. Sometimes, the rise in temperature can reach values of about $5-6{ }^{\circ} \mathrm{C}$ above the mean seasonal values at SPSC. This can explain the premature awakening of animals in hibernation (bats, insects, amphibious and reptiles) and premature larva development. This unusual animal behaviour is short temporal term precursor, usually 12-15 hours before.

\subsection{Fish Deaths}

When the death of fish is not due to pollution, it can be due to an increase in the water temperature of rivers and lakes and/or to the emission of warm and dangerous gas (radon, sulphurous gasses, hydrocyanic anhydrite, ozone, $\mathrm{CO} 2 \ldots$...) that causes fish death. Three days before the two earthquakes of $\mathrm{M}=4.6,19: 14 \mathrm{LT}$, and $\mathrm{M}=4.8,19: 15 \mathrm{LT}$, both occurred the August $21^{\text {st }}, 2000$, in the provinces of Asti and Alessandria, it was reported in Torre Pellice the death of all fishes of a little artificial lake fed by the Biglione creek, whose temperature rise was of $6^{\circ} \mathrm{C}$, temperature recorded in the night. Some frogs and fresh water shrimps dead near Biglione were also noted. The first shock was preceded by 9 small seismic shocks and followed by over 100 seismic shocks until the end of October 2000. A connection between pre-shocks and the death of fish due to a complex synergy of dangerous elements was supposed: on August $10^{\text {th }}$ near Biglione creek and in basement of SPSC a $56.0 \mu \mathrm{S} / \mathrm{h}$ of radioactivity $(\beta+\gamma$ particles $)$ and radon values of 1,517 $\mathrm{Bq} / \mathrm{m}^{2}$ in air ( $\alpha$ particles) were recorded; then, the increase in temperature of the water (recorded at 2:00 a.m.) in a shallow creek may have reduced oxygen in the water, white dust may have changed the $\mathrm{pH}$ in the water and on soil; these variations in a short time could induce death to fishes and other animals.

\subsection{Animals Seek Safety}

Animals have often saved people, in houses about to fall down and in open country, before earthquakes or landslides $[19,20]$. Before the earthquake of April $2^{\text {nd }}, 1808$, at 17:43 LT, with magnitude $M=5.7$ [3], with epicentre in Luserna San Giovanni (as stated above) a woman of San Germano and her sons were saved due to the cows cries, so other people inside houses saved themselves, thanks to the agitation of their cows a few seconds before the seismic shock. This confirms phase C.

Farm animals seek safety from cow-houses, barns or pens. A local weak earthquake in Val Pellice, occurred on May $28^{\text {th }}, 2008$, during a severe rainstorm, caused at the same time four landslides: two on Vandalino Montain, one at Rorà and one at Villar Pellice, killing four people. Half an hour before the seismic event and landslides a male goat saved all his female goats, guiding them away from their pen, which was subsequently destroyed. He returned with his herd the following day.

\subsection{Oxidative Phenomena}

Oxidative phenomena on gneiss surfaces parallel to the ground, near SPSC, occurred 2 days before an earthquake of $\mathrm{M}=4.6$, located in Incisa Scapaccino (August $21^{\mathrm{st}}, 2000$ ). The gneiss of Luserna is normally grey, but on the morning of August $19^{\text {th }}, 2000,9: 30 \mathrm{LT}$, the surface parallel to the ground of all window-sills and steps of gneiss in SPSC gradually begun to turn white. Butterflies and ladybirds were attracted by the white dust on the surfaces (Figure 9). In the morning of August 21 two persons of Torre Pellice and one person of Barge referred that a snake entered inside their houses at the first floor. These persons had also noted some days before the seismic event the oxidation on gneiss steps.

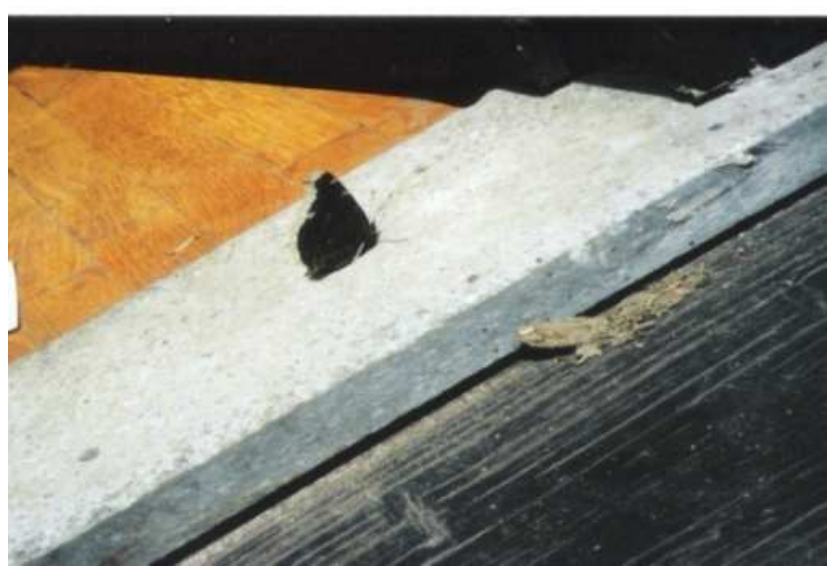

Figure 9. Oxidative phenomena on gneiss surfaces parallel to the ground, near "SPSC", two days before a seismic event with $M=4.6$, located in Incisa Scapaccino (August 21 $1^{\text {st }}$ 2000).

\subsection{The Unusual Reptile and Limacidae Behaviour and pH Water}

While the majority of animal species seeks safety outside, a few species, such as reptiles, generally seek safety going 
inside houses 3-5 hours before a local earthquake. They yearn for dry places; if you let them enter inside, without scaring them, you can observe they take shelter in wool blankets, the same behaviour was noted at SPSC in toads, frogs, stag beetles and even Limacidae.

It is interesting to observe how some of these species are behaving strangely as they usually like humidity whereas wool is hydro-repellent. Two days before the seismic event of October $3^{\text {rd }}, 2012$, epicentre in Sampeyre (16 km to SPSC) and $\mathrm{M}=3.9$, the Limacidae were moving in the fields standing on a fifth or their foot: they were probably escaping from the humid ground. The ground water $\mathrm{pH}$ was 10.5 , so it is possible to suppose that the new chemical and physical properties of the soil water were the cause of this unusual behaviour. During the whole month before this earthquake, it was recorded in SPSC a radon emission mean values around $259 \mathrm{~Bq} / \mathrm{m}^{2}$, while five hours before the shock the mean value were $40.7 \mathrm{~Bq} / \mathrm{m}^{2}$. Air and water ionization and the water mineralization could explain this behaviour. Dehydrated Limacidae was found dead in the field, the day after this seismic event. Zeolite dust on rocks (dehydrating action and ionic exchange), was also observed. In Figure 10 are reported radon monitoring values in SPSC for the January-December 2012 period.

Two days before the Incisa Scapaccino's earthquake on August $21^{\text {st }}, 2000, \mathrm{M}=4.9$, the radon emission values were $1517 \mathrm{~Bq} / \mathrm{m}^{2}$ in the basement of SPSC and immediately outside, a viper and an unknown snake climbed at the first floor, by run-ladder.

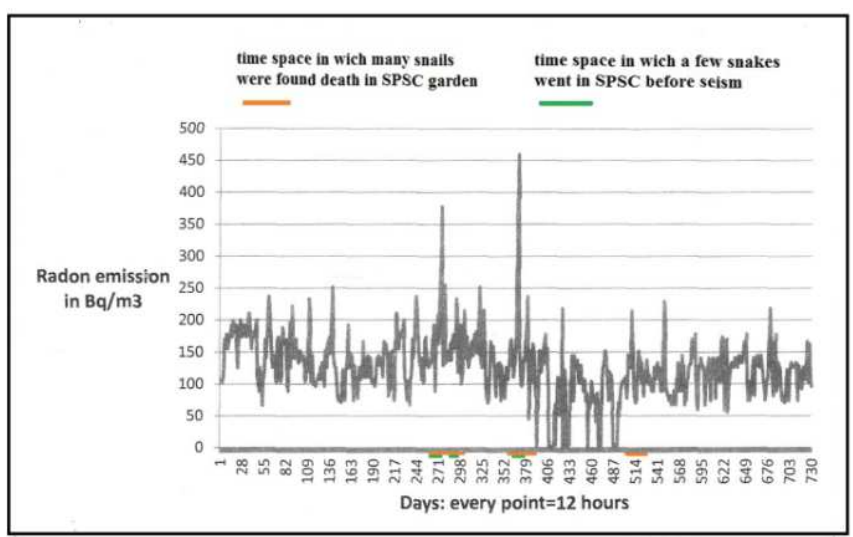

Figure 10. Radon monitoring during January-December 2012; colored horizontal lines indicates anomalous behavior of snails and snakes

\subsection{Zeolite and Ladybirds}

Contrary to reptiles, amphibious, mollusks and some insects, to which zeolite dust can be dangerous, ladybirds appear in great number before earthquakes and voraciously eat the zeolite dust.

This was observed during the first days of 2013 in Rorà and Torre Pellice (Figure 11), a few days before some earthquakes in Briançon and Cesana, February 26, 27 and March 2, 2012, M = 4.0-4.5, distance $20 \mathrm{~km}$ to SPSC.

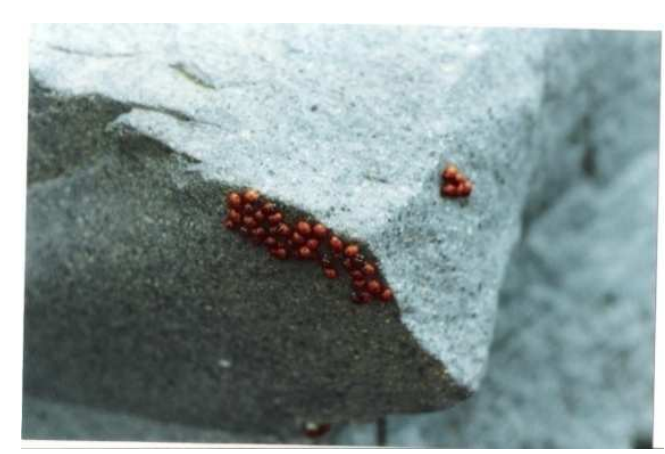

Figure 11. Ladybirds voraciously eating the zeolite dust, before an earthquake of $M=4.6$, Incisa Scapaccino (August $21^{\text {st }}$ 2000).

\subsection{Heavy Damages to the Health}

Damages to people and animal health were observed at SPSC, in connection with measured high radon values. A rapid evolution of pathologies, especially dermatological effects, was reported at SPSC when the radioactive emission was much higher than the local average values. Some examples: from February 6th, 2000, until the end of October 2000, around some houses near Castelluzzo (Torre Pellice), near the Biglione and Angrogna creeks and around the SPSC, a white dust was deposited. At the beginning the dust deposition was massive, then progressively decreasing until the end of July, then there was a consistent deposition of white dust at the beginning of August 2000 (Figure 12). On February $12^{\text {th }}$, four people, including one of the authors (de Liso) went to the Valdese Hospital of Torre Pellice for respiratory and dermatological problems (Figure 13a). Two of the mentioned persons had their houses covered by the white dust: on the lower part of the walls, on the roofs, on the floors. A Pomeranian dog living in SPSC had respiratory and dermatology problems.

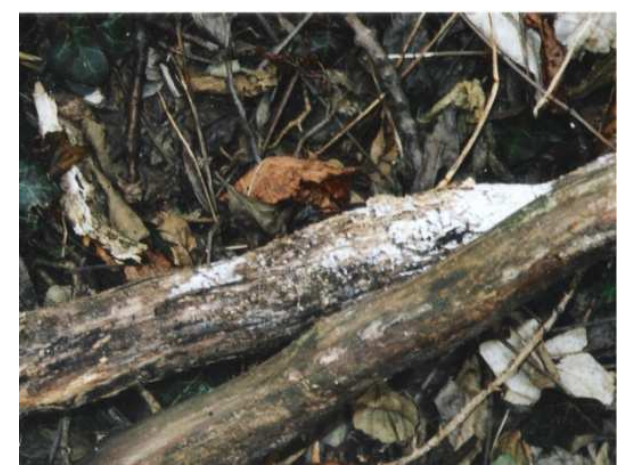

Figure 12. White dust on leaves, near SPSC before a seismic event with $M$ = 4.6, Incisa Scapaccino (August $21^{\text {st }}$ 2000).

On February $12^{\text {th }}, 2000$, the radioactivity around SPSC reached several times the value of $14.9 \mu \mathrm{S} / \mathrm{h}$. The same phenomenon occurred the following year, when high radioactivity and white dust were reported. On February $14^{\text {th }}$, 2001, the radioactivity was $34.9 \mu \mathrm{S} / \mathrm{h}$ inside the house of SPSC, a white dust covered the basement's floor and the meadow outside, so the Pomeranian dog licked its paws, dirty of dust, and on February $15^{\text {th }}$ he died, after respiratory 
complications (Figure 13b). He also inhaled this dust. Other dogs died in the following weeks and people thought the cause was presumably due to poisoning. The author de Liso contracted pneumonia by contact.
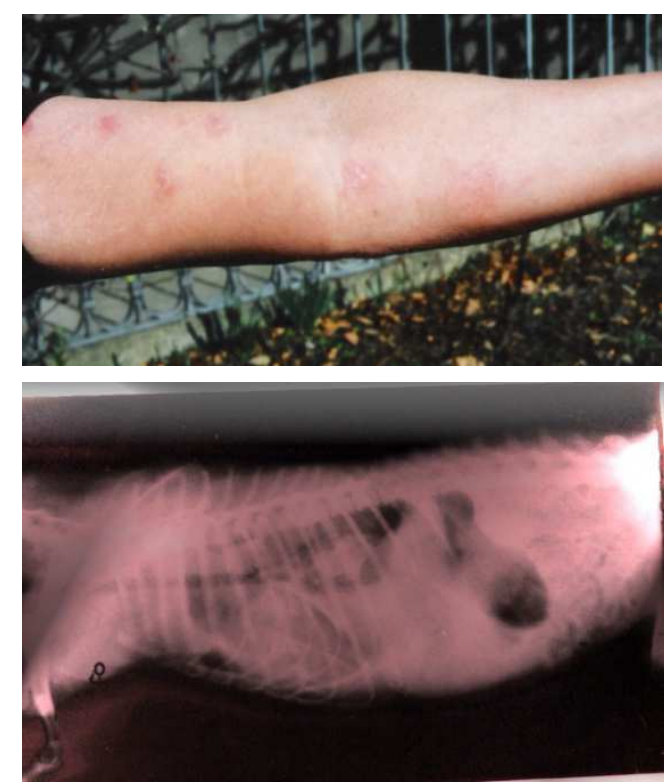

Figure 13. (a): dermatitis with desquamations; (b): radiography of Pomeranian dog showing pulmonary pathology after dust inhalation and exposure to ionizing radiations.

\section{Statistical Behaviour of Dogs and Cats}

A statistical study of unusual animal behaviours before earthquakes in Western Piedmont has been completed, by analysing part of data represented in Figure 5a. The early warnings from dogs and cats were considered before 39 earthquakes around SPSC. The earthquakes were chosen depending on magnitudes and distances, approximately
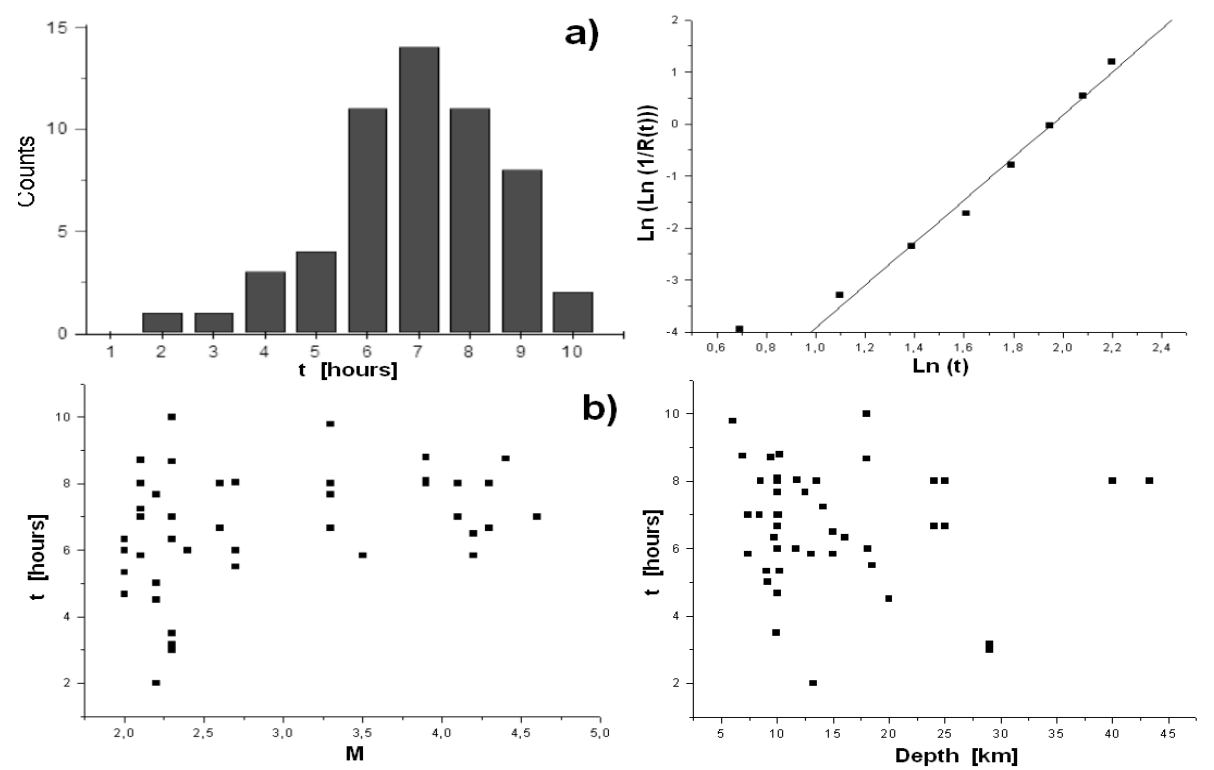

Figure 14. (a) statistical distributions of phase A of dogs and cats behaviour from Table 1; (b) magnitudes and epicentre depths versus Log T. 
Table 1. List of earthquake around SPSC to be considered in connection with dog cries and cat hiding; Time (hh,mmss) were considered in LT; Depth is the depth of the earthquake hypocentre; Distance is the distance between the epicentre and the animal observation location; Dog and Cat columns represent observation times (in $h$ ) before the first shock.

\begin{tabular}{|c|c|c|c|c|c|c|c|}
\hline & Date $[\mathrm{mm} / \mathrm{gg} / \mathbf{a a}]$ & Time [hh,mmss] & Depth [km] & Distance [km] & Magnitude $\left[M_{w}\right]$ & Dogs [h] & Cats [h] \\
\hline 1 & $08 / 21 / 00$ & $17,14^{\prime}$ & 7,4 & 91,7 & 4,6 & 7 & 7 \\
\hline 2 & $07 / 18 / 01$ & $22,47^{\prime}$ & 15 & 91,7 & 4,2 & 6,5 & 5,83 \\
\hline 3 & $09 / 26 / 05$ & 4,20'38" & 29 & 30,4 & 2,3 & 3 & 3,12 \\
\hline 4 & $10 / 31 / 06$ & 20,11'08" & 9,9 & 18,4 & 2,3 & 3,5 & 3,5 \\
\hline 5 & $08 / 29 / 08$ & $15,24^{\prime} 23^{\prime \prime}$ & 13 & 28,3 & 2,1 & 5,83 & 5,83 \\
\hline 6 & $10 / 10 / 08$ & 13,55'39" & 9,1 & 39,2 & 2,2 & 5 & - \\
\hline 7 & $10 / 24 / 08$ & $4,06^{\prime}$ & 10 & 97,5 & 4,1 & 7 & 7 \\
\hline 8 & 03/19/09 & $12,39^{\prime} 50^{\prime \prime}$ & 43,3 & 51,7 & 4,1 & 8 & - \\
\hline 9 & 03/23/09 & 20,01'09" & 10 & 36,4 & 2 & 6 & - \\
\hline 10 & 04/19/09 & $13,39^{\prime}$ & 40 & 65 & 3,9 & 8 & 8 \\
\hline 11 & $05 / 14 / 10$ & $7,55^{\prime}$ & 9 & 35 & 2 & 5,33 & - \\
\hline 12 & $09 / 29 / 10$ & 3,46'42" & 10 & 62 & 3,3 & 7,67 & - \\
\hline 13 & $11 / 11 / 10$ & $18,24^{\prime} 18^{\prime \prime}$ & 13,5 & 14 & 2,1 & 8 & - \\
\hline 14 & $11 / 11 / 10$ & $21,57^{\prime} 30^{\prime \prime}$ & 13,2 & 24 & 2,2 & 2 & - \\
\hline 15 & $11 / 14 / 10$ & 20,31'58" & 12,5 & 27,9 & 2,2 & 7,67 & - \\
\hline 16 & $12 / 18 / 10$ & $21,53^{\prime}$ & 18 & 18 & 2,3 & 10 & 8,67 \\
\hline 17 & $12 / 22 / 10$ & $11,02^{\prime}$ & 24 & 6 & 2,6 & 8 & 6,67 \\
\hline 18 & $04 / 19 / 11$ & 21,04'41" & 18,5 & 45 & 2,7 & 5,5 & 5,5 \\
\hline 19 & $07 / 23 / 11$ & 16,56'53" & 20 & 25,3 & 2,2 & 4,5 & 4,5 \\
\hline 20 & $07 / 25 / 11$ & $12,31^{\prime 2} 20^{\prime \prime}$ & 25 & 17,2 & 4,3 & 8 & 6,67 \\
\hline 21 & $01 / 26 / 12$ & $3,23^{\prime} 52^{\prime \prime}$ & 10,2 & 23,3 & 2 & 5,33 & - \\
\hline 22 & $02 / 02 / 12$ & 18,22'39" & 10,2 & 32 & 3,9 & 8,78 & - \\
\hline 23 & $02 / 05 / 12$ & 7,26'14" & 8,5 & 51,6 & 2,1 & 8 & - \\
\hline 24 & $02 / 05 / 12$ & $16,42^{\prime}$ & 8,4 & 31 & 2,1 & 7 & - \\
\hline 25 & $02 / 26 / 12$ & 22,37'55" & 6,9 & 49,4 & 4,4 & 8,75 & - \\
\hline 26 & $02 / 26 / 12$ & 23,39'34" & 6 & 48,9 & 3,3 & 9,78 & - \\
\hline 27 & $02 / 27 / 12$ & $16,31^{\prime 2} 20^{\prime \prime}$ & 7,4 & 51,8 & 3,5 & 5,83 & - \\
\hline 28 & $02 / 29 / 12$ & $5,44^{\prime} 09^{\prime \prime}$ & 11,8 & 16,5 & 2,7 & 8,03 & - \\
\hline 29 & $09 / 29 / 12$ & 21,06'32" & 10 & 39,4 & 2 & 4,67 & - \\
\hline 30 & $10 / 03 / 12$ & 9,20'43" & 10,02 & 43 & 3,9 & 8,08 & 8,08 \\
\hline 31 & $10 / 04 / 12$ & $17,27^{\prime} 47^{\prime \prime}$ & 16,1 & 39 & 2,3 & 6,33 & 6,33 \\
\hline 32 & $10 / 05 / 12$ & $15,09^{\prime} 01^{\prime \prime}$ & 11,7 & 38 & 2,4 & 6 & - \\
\hline 33 & $12 / 31 / 12$ & $12,48^{\prime} 06^{\prime \prime}$ & 18,1 & 39,5 & 2,7 & 6 & - \\
\hline 34 & $04 / 07 / 13$ & $3,13^{\prime} 11 "$ & 10 & 54 & 3,3 & 8 & 6,67 \\
\hline 35 & $04 / 13 / 13$ & 17,30'38" & 10,1 & 35 & 2,3 & 7 & - \\
\hline 36 & $04 / 13 / 13$ & 19,15'37" & 10 & 39 & 2,1 & 7 & - \\
\hline 37 & $04 / 17 / 13$ & 13,37'39" & 14,1 & 28,2 & 2,1 & 7,23 & - \\
\hline 38 & $05 / 05 / 13$ & 5,33'35" & 9,7 & 40 & 2 & 6,33 & - \\
\hline 39 & $05 / 06 / 13$ & 9,5455" & 9,4 & 30 & 2,1 & 8,72 & 8,72 \\
\hline
\end{tabular}

\section{Conclusions}

The moderate seismic area around SPSC in Torre Pellice, Italy, was characterised by several phenomena regarding unusual animal behaviour and human diseases. Recently, chemical and physical measurements were intensified in the monitoring activity of the area. Comparison "a posteriori" with local seismic activity can be resumed in the following points:

( $\alpha$ ) many cases of strange animal behaviours are reported a few days before a seismic event, contemporaneously to the magnetic sudden commencement;

( $\beta$ ) some species show a particular tripartite sequence in their calls. Phase A, lasting up to 2 hours, $0.5-10$ hours before moderate and near seismic activity; phase B characterized by the absence of alarm calls and finally phase C immediately before (20-40 seconds) the seismic shock characterized by alarm signals probably associated to particular infra-sound emission;

$(\chi)$ oxidative phenomena on plant structures and on ferromagnetic rocks, occurring along surfaces parallel to the ground;

( $\delta$ ) dust deposition, especially alluminates, silicon-alluminates, zeolites;

(ع) gas emission, especially sulphurous gas, hydrocyanic anhydrite, ozone deduced by the olfactory perception of people living in the countryside;

$(\phi)$ increased emission of Radon ${ }^{222}$ in the air above average values ( $\alpha$ particles), and an increase of $\beta$ and $\gamma$ 
emission before the seismic shocks;

$(\gamma)$ variation in the $\mathrm{pH}$ values of water, on meadows and in rivers;

( $)$ variations in the magnetic declination and magnetic intensity;

(1) increase of the temperature in the subsoil contemporaneously to increased radon and gas emission.

Statistics of early strange behaviours in dogs and cats confirm previous results obtained from other observations, in this case it can be stated very precisely that the average warning time is about 6 hours. In contrast to past results, a little magnitude dependence occurs for small earthquakes. These particularities are probably due to the way of collecting information, which permits observations from restricted area to be correlated to small local seismic activity, contrarily to data relative to strong earthquakes from other regions of the world.

Scientific knowledge of pre-seismic phenomena is still in its infancy. Certainly, unusual animal behaviours can give a significant contribution to increase the sensibility to environmental changes. However, the separation and identification of the physical and chemical variables result to be fundamental in order to understand the processes taking places before earthquakes. These can be suggested by the work of Prof. Alberto Carpinteri and his staff of Turin Politecnico, which have experimentally proved that "Luserna Stone" shows piezoelectric and piezomagnetic properties, and piezonuclear characteristics, with neutrons emission when a heavy compression cracks the rocks [33]. To verify the possible connection with these laboratory results, a well controlled multi-parameter monitoring is required and this study is a first effort in this direction. A systematic and statistical study on health problems should be included. It is also opportune to remember popular sayings as "seismic weather", "if the cock sings unusually three times, it is next a ruin", "the rocks in the rustic houses play the tic-tac of San Bernardo, so it is next an earthquake or a war", "the soil is warm, a seismic event is close". These sayings are the result of hundred observations by people, which had a closer contact with nature and animals

\section{Acknowledgements}

The authors would like to thank Angelo Agostino, Alberto Carpinteri, Giulio Fanti, Giampaolo Giuliani, Francesco Lattarulo, Giovanni Martinelli, Paola Michelin, Riccardo Sandrone, Alessandro Vaio and Paolo Volpe for their comments and suggestions on this paper.

\section{References}

[1] Compagnoni, R.; Sandrone, R. Lineamenti geo-petrografici delle Alpi Cozie Italiane tra la Val di Susa e la Val Po, Federazione Piemontese di Mineralogia e Paleontologia, Torino, 1981.
[2] Costa, G.; Panza, G. F.; Suhadolc, P.; Vaccari, F. Zoning of the Italian territory in terms of expected peak ground acceleration derived from complete synthetic seismograms, J. Appl. Geophys., 1993, 1-2, 149-160.

[3] Boschi, E.; Ferrari, G.; Gasperini, P.; Guidoboni, E.;Valensise, G. Catalogo dei Forti Terremoti in Italia dal 461 a.C al 1980, ING-SGA, Bologna, 1995; pp. 974.

[4] Reycend, J. J. Lettre d'un ancien militaire à un dame de Turin. In Corrispondence Vaudoise, Turin, 1908, pp. 13-14.

[5] Viotto, A. Realization of a ground electrical current monitoring in Piedmont in 2010, following the circuital scheme proposed by the geologist Dr. Kurt Dietric, at http://www.vlf.it/kurt/elf.html.

[6] Fidani, C.; Albarello, D.; Arcaleni, M.; Martinelli, G.; Siciliani, P. M.; Tardioli, S.; Vannucchi, A. Emilia earthquake: VLF transmitters and ELF signal from the Central Italy Electromagnetic Network (CIEN). In Atti del 31 GNGTS, November 20-22, 2012, Potenza, pp. 415-420.

[7] De Liso, G.; Lattarulo, F.; Viotto, A. Piezonuclearità, piezoelettricità e piezomagnetismo delle rocce di gneiss e caratterizzazione territoriale della fenomenologia sismica nel Piemonte occidentale, nuove prospettive di studi, In Atti del $30^{\circ}$ Convegno Nazionale GNGTS, 14-17 Novembre, 2011, Trieste, pp. 603-604.

[8] Rikitake, T. Earthquake prediction, Earth Sci. rev., 4, 1968, pp. 245-282.

[9] Rikitake, T. Previsione dei ierremoti, Dario Flaccovio Ed., 1987, pp. 9-17.

[10] Fidani, C. Electromagnetic signals recorded by Perugia and San Procolo (Fermo) stations before the L'Aquila earthquakes, In Atti del 28 GNGTS, November 16-19, 2009, Trieste, pp. 370-373.

[11] Fidani, C. ELF signals by Central Italy electromagnetic network in 2008-2010, In Atti del 29 GNGTS, October 28-30, 2010, Prato, pp. 175-179.

[12] Fidani, C. L'Aquila earthquake: signal intensities of electric field anomalies, In Atti del 30 GNGTS, November 14-17, 2011, Trieste, pp. 363-365.

[13] Fidani, C. Central Italy Electromagnetic Network (CIEN), In Atti del 30 GNGTS, November 14-17, 2011, Trieste, pp. 365-368.

[14] Fidani, C. The Central Italy Electromagnetic Network and the 2009 L'Aquila earthquake: observed electric activity, geosciences, 1, 2011, pp. 3-25.

[15] Viotto, A. Realised the mechanical variations on vertical axis which are recorded in $\mu \mathrm{V}$ by an iron-core inductor, only seismic tremors are recorded on vertical axis.

[16] Meloni, A. Il pianeta magnetico - Introduzione al magnetismo, Ed. NIS, La Nuova Italia Scientifica, 1993;

[17] Fidani, C. Biological anomalies before the 2009 L'Aquila earthquake, animals, this special issue, 2013.

[18] Antsyferov, M.S. On the possibilities of geo-acoustic prediction of local earthquakes. In Acta 3rd All Union Symp. Seismic Regime, June 3-7 1968, Shenze Press, Siberian Division, 1969. Translate into English from Russian by D. B. Vitaliano U. S. Geological Survey. 
[19] Caputo, M. Sismologia e segnali precursori dei terremoti, Calderini Editore, 1987.

[20] Foresta Martin, F.; Polizzi, P. Terremoto, Roma, Avverbi Editore, 1998.

[21] Ikeya, M. H.; Matsumoto, H.; Huang, Q. B. Alignment of silkworms as seismic anomalous behaviour ASSAB and electro-magnetic model of a fault: a theory and laboratory experiment, Acta Seismologica Sinica, 11, 1998, pp. 365-374.

[22] Tributsch, H. When the Snakes Awake: Animals and Earthquake Prediction; MIT Press: Cambridge, MA, USA, 1982.

[23] Lacidonia, G.; Manuello, A.; Carpinteri, A.; Niccolini, G.; Agosto, A.; Durin, G. Acoustic and electromagnetic emissions in rocks under compression, Proocendings of SEM Annual Conference, June 7-10, 2010, Indianapolis, USA, pp. 57-64.

[24] De Liso, G. Caratterizzazione del territorio nell'individuazione dei precursori sismici locali nel Piemonte Occidentale, In Atti del $29^{\circ}$ Convegno Nazionale GNGTS, October 28-30, 2010, Prato, pp. 208-211.

[25] Lavecchia, G.; de Nardis, R.; Cirillo D.; Brozzetti, F.; Boncio, P. The May-June 2012 Ferrara arc earthquake (northern Italy): structural control of the spatial evolution of the seismic sequence and of the surface pattern of coseismic fractures, Ann. Geophys., 55, 4, 2012, pp. 533-540.

[26] Bindi, D.; Pacor, F.; Luzi, L.; Massa, M.; Ameri, G. The Mw $=6.3,2009$ L'Aquila earthquake: source, path and site effects from spectral analysis of strong motion data, Geophys. J. Int., 179, 2009, pp. 1573-1579.

[27] Francia, P.; Villante, U. Some evidence of ground power enhancements at frequencies of global magnetospheric modes at low latitude, Ann. Geophys., 15, 1997, pp. 17-23.

[28] Dobrovolsky, I.P.; Zubkov, S.I.; Miachkin, V.I. Estimation of the size of earthquake preparation zones. Pure Appl. Geophys., 117, 1979, pp. 1025-1044.

[29] Rikitake, T.; Biosystem behaviour as an earthquake precursor, Tectonophysics, 51, 1978, pp. 1-20.

[30] Weibull, W.; A statistical distribution function of large applicability, J. Appl. Mech.-Trans. ASME, 18 (3), 1951, pp. 293-297.

[31] Rikitake, T.; Earthquake prediction work in Sichuan Province, China, with special reference to the Songpan-Pingwu earthquakes, Chinese Geophys., Am. Geophys. Un., 2, 1982, pp. 139-156.

[32] Rikitake, T. Prediction and Precursors of Major Earthquakes, Terra Scientific Publishing Company: Tokyo, Japan, 2003.

[33] Carpinteri, A.; Lacidogna, G.; Manuello, A.; Borla, O. Piezonuclear Transmutations in Brittle Rocks under Mechanical Loading: Microchemical Analysis and Geological Confirmations, In Symposium on Recent Advances in Mechanics, Academy of Athens, Athens, Greece, 17-19 September, 2009, book part III, pp. 361-382, Editors Anthony N. Kounadis, Emmanuel E. Gdoutos, Editors Affiliations: Academy of Athens, Dept. of Civil Engineering, Democritus University of Thrace. 